\title{
The effect of a high glucoraphanin broccoli diet on cardiovascular risk profile: a randomised controlled study
}

\author{
C. N. Armah ${ }^{1}$, M. H. Traka ${ }^{1}$, J. R. Dainty ${ }^{1}$, J. F. Doleman ${ }^{1}$, J. F. Potter ${ }^{2}$ and R. F. Mithen ${ }^{1}$ \\ ${ }^{1}$ Food and Health Programme, Institute of Food Research, Norwich Research Park, Norwich, NR4 7UA, UK and ${ }^{2}$ Faculty \\ of Medicine and Health Sciences, University of East Anglia, Norwich Research Park, Norwich, NR4 7TJ, UK
}

In the UK, cardiovascular disease (CVD) affects more than five million people with estimated annual costs exceeding $£ 30$ bn ${ }^{(1)}$. Epidemiological evidence suggests an inverse relationship between the consumption of cruciferous vegetables and a wide range of cancers and $\mathrm{CVD}^{(2-5)}$. However, despite this evidence for the biological activity of isothiocyanates, an active compound in cruciferous vegetables thought to be responsible for their beneficial effects, there have been few dietary intervention studies in humans that have explored the underlying mechanisms ${ }^{(6)}$.

A novel high glucoraphanin (HG) cultivar of broccoli has been developed by conventional plant breeding. This broccoli has a threefold greater level of glucoraphanin than the standard variety and subsequently delivers a threefold greater level of the isothiocyanate sulforaphane to the systemic circulation ${ }^{(7,8)}$. To explore the role of HG broccoli and the potential role of SF in reducing CVD risk, a 12 week, three armed parallel group, randomised controlled trial (double blinded for two of the three arms) with 48 participants aged 50-77 years, that compared the effects of a diet enriched with either $400 \mathrm{~g}$ of standard broccoli or HG broccoli or $400 \mathrm{~g}$ of garden peas was taken in Norfolk, UK. Participants were defined as having a moderate risk of CVD which was estimated using the JBS2 CVD risk assessor and allocation to study arms was achieved using a minimisation method. In order to assess the effect of the intervention on CVD risk, biochemical markers of CVD (Total/HDL/LDL cholesterol, serum triglycerides, oxidised LDL, IL6, hs-CRP, and analysis of 346 plasma metabolites) and vascular measurements (BP, pulse wave velocity and augmentation index) were obtained. Results were also stratified by GSTM1 genotype.

The HG broccoli intervention resulted in a significant reduction in the ten year CVD risk (mean reduction $-8.1 \% ;-1.0,-15.1,95 \%$ CI, $p=0.03)$, total cholesterol $\left(-0.27 \mathrm{mmolL}^{-1} ; 0.0,-0.47,95 \% \mathrm{CI}, p=0.05\right)$, LDL cholesterol $\left(-0.27 \mathrm{mmolL}^{-1} ;-0.07,-0.47\right.$, $95 \% \mathrm{CI}, p=0.01)$, and reductions in systolic blood pressure amongst many but not all participants $(-2.8 \mathrm{mmHg} ;+0.83,-6.41,95 \% \mathrm{CI}$, $p=0.12)$. These changes were accompanied by reduction in serum levels of medium and long chain acylcarnitines, and a reduction in pro-inflammatory lysophosphatidylcholines. A greater reductions in CVD risk $(-11 \% ;-2.8,-20.6,95 \% \mathrm{CI}, p=0.02)$, LDL cholesterol $\left(-0.30 \mathrm{mmolL}^{-1} ;-0.08,-0.52,95 \% \mathrm{CI}, p=0.02\right)$, systolic blood pressure $(-5 \mathrm{mmHg} ;-1.3,-8.3,95 \% \mathrm{CI}, p=0.01)$ and lysophosphatidylcholines were observed in individuals with at least one GSTM1 allele. The standard broccoli interventions did not result in any significant changes in calculated CVD risk or associated biomarkers. The pea intervention resulted in a significant reduction in systolic blood pressure (mean reduction $-3.7 \mathrm{mmHg} ;-0.04,-7.36,95 \% \mathrm{CI}, p=0.05$ ).

These results suggest that consuming HG broccoli for 12 weeks led to a clinically significant reduction in the cardiovascular risk of participants with moderate baseline risk due primarily to modifications in lipid metabolism.

This study was funded by Biotechnology and Biological Sciences Research Council (BBSRC) and Seminis Vegetable Seeds Inc. Trial registration, Clinical Trials NCT01114399.

1. Luengo-Fernandez R, Leal J, Gray A, Petersen S, Rayner \& Heart M (2006) Oct 92(10): 1384-9.

2. Hansson L, Nyrén O, Bergström R, Wolk A, Lindgren A, Baron J \& Adam IHO (1993) Int J Cancer 9(55(2)): 181-9.

3. London S, Yuan JM, Chung FL, Gao YT, Coetzee GA, Ross RK \& Yu MC (2000) Lancet 356(9231): 724-9.

4. Zhao H, Lin J, Grossman HB, Hernandez LM, Dinney CP \& Wu X (2007) Int J Cancer 120(10): $2208-13$.

5. Traka M \& Mithen R (2009) Phytochem Rev. 8, 269-82.

6. Traka MH \& Mithen RF (2011) Plant Cell. Jul 23(7): 2483-97.

7. Mithen R, Faulkner K, Magrath R, Rose P, Williamson G \& Marquez J (2003) Theor Appl Genet. Feb 106(4): 727-34.

8. Gasper AV, Al-Janobi A, Smith JA, Bacon JR, Fortun P, Atherton C et al. (2005) Am J Clin Nutr. Dec;82(6): 1283-91. 